ГORIGINAL ARTICLE-

Volume 13 Issue 32021

DOI: 10.21315/eimj2021.13.3.8

ARTICLE INFO

Received: 04-02-2021

Accepted: 22-06-2021

Online: 30-09-2021

\section{How to Prepare for the Membership of the Royal College of Physicians (UK) Part 2 Clinical Examination (Practical Assessment of Clinical Examination Skills): An Exploratory Study}

\author{
Eugene S Henry ${ }^{1}$, Naomi Quinton ${ }^{2}$ \\ ${ }^{1}$ Emergency Department, Pinderfields General Hospital, Wakefield, \\ UNITED KINGDOM \\ ${ }^{2}$ Leeds Institute of Medical Education, University of Leeds, Leeds, \\ UNITED KINGDOM
}

To cite this article: Henry ES, Quinton N. How to prepare for the Membership of the Royal College of Physicians (UK) Part 2 Clinical Examination (Practical Assessment of Clinical Examination Skills): an exploratory study. Education in Medicine Journal. 2021;13(3):77-91. https://doi.org/10.21315/ eimj2021.13.3.8

To link to this article: https://doi.org/10.21315/eimj2021.13.3.8

\title{
ABSTRACT
}

The Practical Assessment of Clinical Examination Skills (PACES) examination is considered the most difficult component of the three-part Membership of the Royal College of Physicians (MRCP) United Kingdom (UK) diploma, which provides budding physicians with access to a diverse pathway of subspecialties and a rewarding medical career. Preparing for the exam is onerous, especially when also juggling work and family demands. This research explored how candidates can prepare for this exam in an organised manner to improve their chances of first-pass success. Semi-structured interviews were conducted with 10 participants in the West Yorkshire region in the UK who had passed the PACES examination within 24 months. The interviews were transcribed onto QSR NVivo software, coded reflexively and analysed using thematic analysis. The analysis identified 25 codes that were aggregated into the following themes according to their density; (a) mental conditioning, (b) clinical exposure, (c) external factors and support, (d) revision courses, (e) knowledge acquisition, (f) playing the objective structured clinical examination (OSCE) game, (g) change of strategy, and (h) novel methods. In summary, it takes more than just clinical exposure and rote learning to pass the exam; preparation involves a complex, multifaceted approach. With proper mental conditioning, organisational skills and confidence, the adverse effect of test anxiety could be reduced to improve chances of success. Peer learning is an effective tool for facilitating examination preparation among candidates, besides providing a supportive framework. Cues from this study could act as a guiding framework for future PACES candidates to further refine their study strategies.

Keywords: PACES, High-stakes examination, MRCP, Medical education, Postgraduate education

CORRESPONDING AUTHOR Eugene S Henry, Department of Emergency, Pinderfields General Hospital, Aberford Road, Wakefield WF1 4DG, United Kingdom

Email: e.henry@nhs.net 


\section{INTRODUCTION}

The Membership of the Royal College of Physicians (MRCP) exam consists of three parts including (a) Part 1, (b) Part 2 written, and (c) Part 2 Practical Assessment of Clinical Examination Skills (PACES) examination. Upon passing Part 1, candidates are allowed to sit for the Part 2 written and the PACES components. The MRCP(UK) diploma is renowned worldwide for its stringent quality and validity (1-2) and is accepted as an "internationally recognised imprimatur" (3). The postnominals of MRCP(UK) are conferred on candidates who have passed all three parts of the examination. Candidates are allowed to attempt each part of the examination a maximum of six times.

The PACES is regarded as a high-stakes examination, as the policy design is based on the strict standards stipulated by the supervisory bodies such as the General Medical Council and the Royal College of Physicians, UK. These standards exist to keep patients and the community safe. High-stakes testing has a significant impact on career demand and consequently leads to test anxiety (4).

In Malaysia, the MRCP is recognised as an alternative pathway towards training in medical specialties (5). Upon passing the exam, doctors are eligible to be registered as clinical specialists in medicine with the National Specialist Register and the Ministry of Health. The physician in training needs to complete a period of gazettement as a specialist under supervision in an accredited hospital. Physicians who pass the MRCP and who have entered the specialist register can then tap into a wide array of subspeciality training, including renal medicine, respiratory medicine, etc., to further progress in their career.

The PACES examination is a clinical examination on real patients under stringent examination settings. It lasts for 125 minutes, in which candidates complete five test stations in a carousel format: (a) Station 1: Respiratory/abdominal

(b) Station 2: History taking

(c) Station 3: Cardiovascular

(d) Station 4: Communication and ethics

(e) Station 5: Brief clinical consultation

Candidates are examined against seven important core clinical skills. The highquality standard expected of the candidates is that of a medical registrar in an acute hospital in the UK, who is responsible for decision-making in the wards. A candidate who is deemed competent is expected to make well calibrated clinical decisions (6-8) under duress. The pass rate for the PACES at the first attempt is about $60 \%$ to $65 \%$ (9). The quoted data are relevant only for UK graduates, and non-UK graduates have an even lower pass rate at the first and subsequent attempts (10-11).

Reasons such as limited spaces for the Masters in Medicine (MMed) programme and the flexibility to sit for the MRCP at one's own pace contribute to why some junior doctors (medical officers) decide to sit for the MRCP examination to gain specialist registration in Malaysia. Consequently, candidates also bear the exorbitant costs in money and time associated with this alternative pathway. Preparation for the exam is mainly self-regulated. At postgraduate level, it is challenging to prepare for these high-stakes examinations, as one has to juggle work, exam preparation and life commitments. The total cost of passing all the components of the exam at the first attempt is $£ 1,495$, which does not include courses, materials and transport costs associated with the exam, which may add up to a significant amount.

The literature review identified that guidance on how to prepare for the MRCP PACES exam is mainly anecdotal, based on the personal viewpoints of one or a few people (12) or of PACES examiners (13). It can be inferred that some advice might not be relevant due to geographical or personal 
circumstances. For example, support frameworks at an organisational level have been shown to improve performance among trainees (14), but this mechanism may not be easily available or even replicable for doctors preparing for the exam outside the UK.

Possible reasons for poor performance in the PACES examination including (a) poor communication skills (10), (b) poor organisational skills (15), (c) poor timing (16), (d) lack of support (14), (e) lack of adequate preparation, and (f) language barriers (13). Some of the non-modifiable factors that predict success in the exam include ethnicity, gender (8), and examiner demeanour (17).

The gaps in the literature and the significance of the exam have provided compelling grounds for research to be carried out using a robust epistemologically grounded approach. At the time of writing, this is the only qualitative research using thematic analysis that addresses the question of how to prepare for the MRCP PACES. Taking into account the cost, the psychological impact of failure and the time commitment involved with preparing for the exam, the first attempt at PACES is considered to be the best attempt. This research aimed to explore how PACES candidates can prepare for the exam in an organised manner to improve one's chances for success at the first attempt.

The research questions for the study are as follows:

(a) How did candidates prepare for the PACES examinations?

(b) What factors influenced a candidate's decision to enter themselves for the PACES examination?

(c) How, if at all, did candidates who re-sat the PACES examination adapt their preparation strategy?

\section{METHODS}

\section{Design and Sampling}

Semi-structured interviews were used as the data collection method. The rationale was that semi-structured interviews would allow a deeper understanding of the principles that underpin the processes involved in the PACES examination through the use of open-ended questioning (18). Relevant cues/ themes in the questionnaire sheets were used to ensure that participants were probed to further elaborate on their experiences to answer the research questions without leading the participant (Figure 1). PACES has a low first-time pass rate. Therefore, with the inclusion of participants who had attempted the exam more than once, the study sample provided a near-accurate representation of a more comprehensive, real-life candidate pool. Besides, the inclusion of re-sit candidates provided the opportunity to answer the research questions (Q1 and Q3) and unearth novel strategies.

Where applicable, the Standards of Reporting Qualitative Research Framework (19) is used to report the specifics of this study.

Ten participants $(n=10)$ (Table 1$)$ were recruited using convenience sampling for the purpose of this study. All participants were junior doctors (non-consultant doctors) working in the West Yorkshire region of the UK and were recruited through a gatekeeper. Data saturation was achieved by the 10th participant (20). Participants were given an information sheet and consent form to sign prior to the interviews. Withdrawal from the study was allowed at any time up to 48 hours after the interview without giving any reason and without any negative consequences. None of the participants withdrew from the study. The electronic forms, transcribed conversations and audio recordings were uploaded into the University of Leeds's M Drive. 


\section{Guiding themes for the semi structured interview}

Me: Dear participant, thank you for agreeing to take part in this research. Your time and contribution are greatly appreciated. I would like to reiterate that the contents of this interview are confidential and identifiable data will be anonymised.

\section{Participant:}

Me: I understand that you have completed PACES, could you tell me at what stage of your medical career did you take the exam?

\section{Theme for discussion}

- Preparation process and study strategy

- Overall experience preparing for the exam and hurdles faced

- Preferred method of preparation

- When did the participant decide it was the right time to sit for the exam and why

- Previous attempts in the exam and change of strategy

- Emotional status

\section{Finally}

Me: Is there aything else that you think is relevant that you would like to add in terms of how you prepared for PACES?

\section{Participant:}

Me: Thank you very much your most valued contribution. All the best in your future endeavours. I will now switch off the recording.

Figure 1: Guiding themes for the semi-structured interviews.

Table 1: Participant demographics

\begin{tabular}{lll}
\hline Participant demographics $(\boldsymbol{n}=\mathbf{1 0})$ & & \\
\hline Gender & Male & Female \\
& $4(40 \%)$ & $6(60 \%)$ \\
Number of attempts & Single attempt & Two or more attempts \\
& $4(40 \%)$ & $6(60 \%)$ \\
Background & UK graduate & Non-UK graduate \\
& $7(70 \%)$ & $3(30 \%)$ \\
Training status* & Trainee & Non-trainee \\
& $5(50 \%)$ & $5(50 \%)$ \\
\hline
\end{tabular}

Note: *Training status defined as having a valid UK National Training Number (NTN) in a deanery-approved training position while attempting the PACES examination. 


\section{Analysis}

The semi-structured interviews were carried out in a private room on the hospital premises and were recorded using a dictaphone with a secure password. The recordings were transcribed directly onto the QSR NVivo software at the outset. The interviews were transcribed nonorthographically (omitting pauses, nonverbal behaviour and utterances). The understanding was that utterances and phonetics would have no impact on the interviewees' perspectives (21), as this was not linguistics research. Identifiable information in the transcripts was pseudonymised and time stamped to ensure accurate data analysis. The interviews and the analysis were conducted concurrently and continued until no new themes emerged and data saturation was felt to be complete.

Braun and Clarke's six-step method of thematic analysis (22) was used to analyse the dataset. The theory driving the analysis was the self-regulated learning (SRL) theory. Historically, thematic analysis (TA) may be perceived as being too flexible and non-adherent to a specific traditional qualitative research protocol (23); in other words "anything goes". However, recent literature (24) has shed increasing clarity on the minutiae of the analytical process (especially theme formation). Therefore, TA in this study was employed in a systematic and deliberate method (25) to maintain rigour. As the study aimed to explore the participants' motivations, the PACES candidates' emotional and behavioural dimensions, distinguishing "sensitising concepts", were utilised to provide "a general sense of reference and guidance in approaching empirical instance" (26) in the analysis.

QSR NVivo software was used for the coding process. To preserve the richness of the data and maintain the context (27), the coding was done completely rather than selectively. This process was further refined later through reading and re-reading the data. The dataset underwent some recoding and revisions $(22,28)$. A codebook with set definitions of each code and theme was created to ensure regularity within the coding process.

\section{Trustworthiness}

Calibration was done first with open coding and then establishing a codebook throughout the research meetings. Both researchers analysed the data, and any discrepancies were adjudicated. Investigator triangulation was carried out with the study supervisor upon completion of data analysis. The approach here is central; a constructivist perspective is used to explore the phenomenon.

The views of Whymark in the textbook Preparing to Pass the FRCA: Strategies for Exam Success (29) about a similar highstakes examination, the Fellowship of the Royal College of Anaesthetists examination, broadly concur with the emerging themes deduced from this research (theoretical triangulation) (30).

The trustworthiness of the data was enhanced by the transparency of the analysis. The analysis and coding remained inductive (bottom up), where the participants' perspectives were the crux in synthesising new themes and at the same time maintaining reflexivity (31).

\section{Ethics}

This study is considered a service evaluation, and thus no clearance was necessary from the National Health Service (NHS) Health Research Authority. Ethical approval from the University of Leeds was granted on 15 May 2019, reference number MREC 18-069. An amendment was approved on 1 October 2019, reference MREC 18-069 Amd 1 Oct 2019, to include a Costa Coffee voucher worth $£ 10$ for the participants and also the flexibility to interview the participants according to their work schedule. 


\section{RESULTS}

The interview analysis identified 25 codes aggregated into themes and subthemes (Table 2). Themes 1 to 6 were ordinary themes while Themes 7 and 8 were unexpected themes that emerged from the study (32).

The emerging themes highlighted the importance of employing multiple approaches towards preparing for the PACES. Many participants had experienced at least one type of hurdle throughout their preparation period (e.g., logistics, shift work issues, bereavement and pregnancy). Methods employed by the participants to manage anxiety included breathing techniques, being organised and psychological interventions (cognitive behavioural therapy or life coaches).
So, once I gathered enough information about the exam, I basically knew which were my weak areas that I needed to target my revision on. I knew that, for me, I needed to see a lot of patients with positive signs to be able to pick them up. So, I knew I had to go to the ward to be able to examine patients. (Participant E)

Self-knowledge, defined as knowledge of one's own motives and character (33), is the first determining step in preparing for the exam. Most of the participants from a non-UK background were aware of the language barrier, as they were non-native English speakers and lacked exposure to the organisational structure of the NHS. These participants then directed remediation efforts towards Stations 2 and 4 of the PACES.

Table 2: Themes and coding densities

\begin{tabular}{llc}
\hline Themes & Subthemes & References \\
\hline Mental conditioning & Managing the hurdles & 52 \\
(Total references: 156) & Confidence & 32 \\
& Self-knowledge & 28 \\
& Anxiety management & 27 \\
& Motivation & 17 \\
Clinical exposure & Peer learning & 26 \\
(Total references: 72) & Senior-led practice & 19 \\
& Clinical experience & 27 \\
"Playing the OSCE game" & & 43 \\
Knowledge acquisition & Technology-enhanced learning & 21 \\
(Total references: 37) & "Bookwork" & 16 \\
Revision courses & Organised by deanery & 15 \\
(Total references: 26) & Paid courses & 11 \\
Change of strategy & & 9 \\
External factors & & 9 \\
(Total references: 29) & Organisational support & 8 \\
& Family/partner support & 12 \\
Novel methods & Examiner demeanour & 11 \\
\hline
\end{tabular}


The awareness on how to approach the station, I worked a lot on. Rather than arriving in a panic without knowing a specific template, which was what happened at the first attempt. (Participant A)

Good time-keeping and organisational skills are essential habits in avoiding uncoordinated preparation.

You need to learn how to play the exam game. I did not really believe it when people told me that. In reality, if you hear a murmur, you would be getting an echo. But you can not just say that in the exam. (Participant J)

It is also important to know what the examiners expect of a candidate to fulfil the requirements to pass.

After the first attempt, I got to know what the exam was and then decided that I had to change the way I practised for the exam. (Participant B)

All the candidates passed their further attempts after changing the way they prepared for the exam based on the results from their previous attempt(s). The interviewees reflected on what went wrong in the previous attempt and put measures in place to rectify the issues highlighted in the college's exam feedback sheet.

The choice of strategy was dependent on factors such as having children, access to support and training status. However, these factors are not limiting factors, and the participants still employed a variety of creative methods to enhance learning, especially when there were no peers to practise with.

Examples of the creative methods that have been employed by the research participants were:

(a) Usage of "memory joggers" to improve recall and presentation skills:
For my first attempt, I got a bowl and put in little pieces of paper with all the conditions you might get for PACES. I would then stand in front of a mirror and would present the findings I would expect for the conditions to myself. Suddenly while presenting you might just notice your knowledge gaps. (Participant G)

(b) Practising with a friend/family member to become slicker at the physical examination routines at home:

I started getting into the routine of examination. It has been a while since I did the whole "textbook" exam routine. It was good to use him because, it is easier for timing. You realise how long it takes for someone to sit up or how long it takes for someone to do things. Just occasionally he would say, "What do you mean?" because he is not a medic. (Participant F)

This study brought to light that having a "PACES buddy" (peer learning) is an effective tool in the preparation journey.

She was a trainee which was taking a foundation year 3 while doing her PACES. She was very keen on revising. She was very organised and wanted to meet up a lot. I felt that it was really good to have someone who was very insistent on revising. I can not think of the word-more like a person who motivates you to prepare, I guess. Someone who is proactive. (Participant H)

Learners hone their physical examination skills and pick up important tips from their "buddy" to help improve their technique and skills. At the same time, some participants look to their "buddies" for emotional support - to build each other up and motivate each other towards a common goal. For the peer learning system to work, both parties should be able to contribute 
equally to each other's learning through constructive feedback.

It is noteworthy that all the interviewees clearly delineated a difference between the learning outcomes of peer-led bedside practice and senior-led teaching.

They made you realise things that you would not have picked up before. For example, how you would present yourself, which is something you would not normally notice if you did it with your friends. They also helped with strategies to answer the questions. And keeping it simple, to be honest. Because they usually ask you simple questions in the exam. (Participant D)

By practising with a senior, learners developed their confidence and refined their techniques and presentation skills. Some participants had the opportunity to practise with consultants who were examiners for the actual PACES exam and benefited from their feedback as a PACES examiner.

In my opinion, before going to the exam centre-if you are confident, one can perform better than expectation. (Participant $\mathrm{C}$ )

Most participants concurred that confidence was an important attribute in the exam. To exude confidence in the examination, candidates have to present their findings using the right body language and tone of speech under the duress of the examination. This skill can be developed through practice under mock exam conditions.

All the participants attested to the importance of attending some sort of revision course before attempting the exam, as it helped with orientation towards the exam. Interviewees who had difficulties practising in the wards due to their work or life commitments found the revision courses to be the most helpful.
The participants who both attended the course organised by the Yorkshire and Humber $(\mathrm{Y} \& \mathrm{H})$ deanery and paid for courses strongly recommended the deanery course due to its organised structure and the focus on individualised feedback, even though the cases seen in the paid courses were significantly esoteric and more in number.

The feedback was really structured. It was like doing four or five exams over the weekend. You had six minutes to examine the patient and then you did not just move straight on-you got five minutes of feedback from that person. You are in pairs-so you could watch someone examining the whole time even if you were not examining. At the end of the course, you would have a sit down with your mentor who would have collated all the feedback from the faculty regarding your strengths and weakness and how you could work on those things. Whereas the one in Manchester-it was like a free for all going into different rooms then coming out and presenting to somebody who would say, "Well, actually that was not that diagnosis, go back and listen again". There was no individualised feedback. (Participant J)

The layout of the Y\&H deanery course was similar to a mock PACES examination. The structure of a course and how it fits with an individual's learning needs are more important than duration or cost. Paying an exorbitant amount for course fees does not guarantee the expected learning outcome.

Some factors are constant, but still undeniably have a significant impact on the candidate's performance from a psychological point of view. One such element was examiner demeanour.

When I got there, the chief examiner said, "We were just getting the patients ready. Just do your best. We want people to do well". 
It kind of relaxed me. I think the examiners were very encouraging. When I walked into the station and knew what it was straight away, I just ate it up. (Participant I)

Some participants in the study perceived that "being nice" was not necessarily regarded as being lenient. However, a warm demeanour did help allay anxiety and negate the malignant effects of test anxiety.

The emerging themes and answers in relation to the research questions are summarised in Table 3.

\section{DISCUSSION}

As Segool (34) has postulated, one of the main components of the cognitive behaviour model that addresses test anxiety in high-stakes examination is self-efficacy. Self-efficacy is defined by the eminent psychologist, Bandura (35), as "how well one can execute courses of action required to deal with prospective situations". This study brings forward a crucial point to ponder for future candidates who aim to attempt the PACES; preparation should start by addressing the known complicating factors in advance. By reflecting on their areas of concern, candidates would be able to further drive self-improvement, which can inform change (36).

Factors such as work schedule, clinical background, demographics and type of personality are pertinent issues to consider when deciding what the best method would be to prepare for the PACES $(1-2,10)$. The importance of a multimodal approach or a combination of methods rather than the usage of a single strategy alone cannot be overemphasised. By approaching the same problem from different angles, candidates can better understand the context of a problem and, in the process, inadvertently discover knowledge gaps.

Table 3: Themes in relation to research questions

\begin{tabular}{|c|c|c|}
\hline Question & Answer & Themes/subthemes \\
\hline $\begin{array}{l}\text { Q1. How did candidates } \\
\text { prepare for the PACES } \\
\text { examination? }\end{array}$ & $\begin{array}{l}\text { Preparing for the PACES requires } \\
\text { a well-nuanced strategy, } \\
\text { incorporating self-efficacy and } \\
\text { self-monitoring measures to } \\
\text { increase the chances of passing } \\
\text { the exam at the first attempt. }\end{array}$ & $\begin{array}{l}\text { Mental conditioning and } \\
\text { subthemes. } \\
\text { "Playing the OSCE game". } \\
\text { Clinical exposure and subthemes. } \\
\text { Knowledge acquisition and } \\
\text { subthemes. } \\
\text { External factors. } \\
\text { Novel methods. }\end{array}$ \\
\hline $\begin{array}{l}\text { Q2. What factors influenced } \\
\text { a candidate's decision to } \\
\text { enter themselves for the } \\
\text { PACES examination? }\end{array}$ & $\begin{array}{l}\text { Participants found that they were } \\
\text { ready to sit for the exam two to } \\
\text { four years after graduating from } \\
\text { medical school. Other factors, } \\
\text { such as motivation, awareness of } \\
\text { limitations, confidence, support } \\
\text { and personal circumstances, play } \\
\text { a part in the decision-making. }\end{array}$ & $\begin{array}{l}\text { Clinical exposure. } \\
\text { Clinical experience. } \\
\text { Confidence. } \\
\text { Motivation. } \\
\text { External support. } \\
\text { Family support and } \\
\quad \text { organisational support. } \\
\text { Self-knowledge. }\end{array}$ \\
\hline $\begin{array}{l}\text { Q3. How, if at all, did } \\
\text { candidates who re-sat the } \\
\text { PACES examination adapt } \\
\text { their preparation strategy? }\end{array}$ & $\begin{array}{l}\text { A change in strategy is mandatory. } \\
\text { Feedback from the mark sheets } \\
\text { from previous attempts from } \\
\text { the college and discussion } \\
\text { with seniors/peers guided the } \\
\text { candidate in addressing areas } \\
\text { of weaknesses to inform change. }\end{array}$ & $\begin{array}{l}\text { Change of strategy. } \\
\text { Clinical exposure and subthemes. } \\
\text { Mental conditioning and } \\
\text { subthemes. } \\
\text { Organisational support. } \\
\text { Family/partner support. }\end{array}$ \\
\hline
\end{tabular}


Non-UK trainees perform less well than their UK-trained counterparts in the communication-based stations (Stations 2 and 4) (37) due to cultural differences and differences in training background. The nuances of this "differential attainment" (38) and the impact of culture differences on examination could be explained by the framework contextualised in Hofstede's cultural dimension theory (39). Even though some factors are non-modifiable (gender, race, etc.), this research suggests that due attention paid to communication skills during preparation would help achieve the descriptors required to pass the PACES. A solid understanding of differential attainment and how to prepare accordingly is relevant to the success of non-UK (Malaysian) doctors who plan to sit for this examination, especially when attempting the PACES in UK centres.

PACES is an OSCE, and candidates are expected to fulfil the requirements of the mark sheets and achieve the minimum descriptors in the construct to pass the exam. It is, however, important to highlight that no marks are given for a particular station. All seven core clinical skills are scored across the five stations, and the pass mark for each skill must be attained to pass the exam. This might seem as though candidates are expected to conform to a specific "professional role reproduction" (40). Nevertheless, the content validity and reliability of the examination is strictly preserved through a regimented examiner calibration exercise prior to each test cycle $(17,41)$.

Even though confidence is key, it is also important to strike a balance, as overconfidence might be interpreted as arrogance and recklessness by the examiners (13).

Through peer learning, candidates work together to pass the exam; thus, their synergistic relationship further enhances learning (42). Peer learning encourages emotional support and extends the zone of proximal development (43) through interaction between "PACES buddies". Peers benefit from feedback that is individualised, critical and constructive during the practice sessions (44). The learning encounters can be further diversified with the presence of facilitators (consultants or registrars/specialists) to help provide objective feedback. It is important for the learner to reflect on the feedback to consolidate the entire learning process. The PACES revision course organised by the $\mathrm{Y} \& \mathrm{H}$ deanery was felt to be useful by the candidates who attended it and could be explained theoretically as it maintains the integrity of the learning cycle loop (45).

Anxiety and anxiety management play a significant role in the period before and during the examination. A healthy amount of anxiety provides the appropriate encouragement for the candidate to excel in this high-stakes examination (46). However, it can be argued that the boundaries between "healthy anxiety" and "harmful anxiety" can be indistinguishable at times. The effects of test anxiety (34) could be alleviated by early recognition of its malignant effects (47) and by tapping into available support frameworks from peers and employers.

\section{STUDY LIMITATIONS}

The sample size $(n=10)$ was small. However, consistent saturation was achieved and preserved in the form of data saturation during the data collection and inductive thematic saturation during the analysis (48). The study population in this research was homogenous. The sampling of this study included junior doctors working in the UK who were exposed to certain levels of support that might not be available to Malaysian candidates. Therefore, accessibility to training, differences in working patterns and undergraduate background are notable factors that may limit the transferability of this research. PACES is a UK-based examination, and 
even though it is attempted by candidates from multiple backgrounds, the standard setting is overseen and governed by the Royal Colleges of Physicians of the UK (London, Edinburgh and Glasgow) (49). The standards and expectations are the same, whether attempted in the UK or externally. The heterogeneity of the sample is regarded as a strength rather than a weakness, as it enabled comprehensive data capture. International medical graduates were included in the sampling, as it is recognised that candidates who graduate from UK medical schools have differing performances in the MRCP(UK) examinations (50).

The differential attainment issues related to gender, type of education and number of previous attempts for the PACES examination are well known. A larger, more robust study might be able to provide greater insight into the challenges and countermeasures employed by these subgroups. Member checking was not carried out, as we felt it might subject unnecessary strain on the participants and take an undue amount of their time. This research was carried out prior to the COVID-19 pandemic and the manuscript was written during the pandemic. With social distancing measures, some methods may appear to be more favourable for preparation, such as technology-enhanced learning. It would be worthwhile for further research efforts to be directed towards exploring the effects of the interruption of the MRCP exams during the pandemic and how candidates changed their preparation methods to adapt accordingly. There is further scope for replication studies to be conducted in other sites (e.g., Malaysia) with a larger sample size informed by the findings from this study. The outcomes of these replication studies could further lead to richer discoveries, with a significant and lasting impact on future candidates sitting for the PACES exam worldwide.

\section{CONCLUSION}

This study found that organisational skills and self-management play an equally important role in preparing for the PACES compared to the old adage of "practice, practice, practice" and knowledge acquisition alone. Peer learning or having a "PACES buddy" is a crucial element, as it encourages development and provides a support framework for candidates when dealing with exam anxiety. Seniorled teaching provides different learning outcomes compared to peer learning when preparing for the PACES. The best time to attempt the PACES is two to four years after graduating from medical school with about three to six months for preparation. This study also unearthed that candidates would benefit from requesting feedback from the college after each failed attempt and changing their strategy accordingly. In summary, it is hoped that the conclusion from this research will provide a robust guiding framework for candidates intending to sit for the PACES examination. Nevertheless, it is not meant to be a prescriptive regime to follow.

The key messages from this research are summarised as follows:

(a) Prepare for the PACES using a multimodal approach.

(b) Reduce stressors by managing the hurdles early.

(c) Non-UK trainees should focus on Stations 2 and 4 during their preparation.

(d) Revision courses should be viewed as avenues to hone one's skills.

(e) One needs to reorientate one's preparation strategy after each failed attempt.

(f) Peer learning using a "PACES buddy" is an effective tool in preparation for the exam.

(g) Candidates should have a good understanding of the expectations of the examination. 


\section{ACKNOWLEDGEMENTS}

We would like to thank Rebecca O'Rourke and Helen Bradbury from the University of Leeds who have provided their unfaltering support as leads for the Master's in Clinical Education Programme (2017-2020). This research and compensation for participants was self-funded.

\section{REFERENCES}

1. Wakeford R, Denney M, Ludka-Stempien $\mathrm{K}$, Dacre J, McManus IC. Crosscomparison of MRCGP \& MRCP(UK) in a database linkage study of 2,284 candidates taking both examinations: assessment of validity and differential performance by ethnicity. BMC Med Educ. 2015;15(1). https://doi.org/10.1186/s12909-014-0281-2

2. McManus IC, Wakeford R. PLAB and UK graduates' performance on MRCP(UK) and MRCGP examinations: data linkage study. BMJ. 2014;348. https://doi.org/10.1136/bmj . $\mathrm{g} 2621$

3. Verghese A. Beyond measure: teaching clinical skills. J Grad Med Educ. 2010;2(1):1-3. https://doi.org/10.4300/ JGME-D-10-00008.1

4. Putwain DW. Test anxiety in UK schoolchildren: prevalence and demographic patterns. Br J Educ Psychol. 2007;77(Pt 3):579-93. https://doi.org/10 .1348/000709906X161704

5. National Specialist Register (NSR) [Internet]. Kuala Lumpur: National Specialist Register; 2013 [cited 2020 Mar 20]. Recognised postgraduate qualification (medicine). Available from: https://nsr.org .my/Qualifications.html.

6. Elder A, McManus C, McAlpine L, Dacre J. What skills are tested in the new PACES examination? Ann Acad Med Singap. 2011;40(3):119-25.
7. McAlpine LG, Kopelman PG. MRCP(UK) Part 2 - clinical examination (PACES): examiners reflections. Clin Med. 2007;7(4):417. https://doi.org/10.7861/ clinmedicine.7-4-417

8. Larkin J. MRCP(UK) Part 2 clinical examination (PACES): examiners reflections. Clin Med (Lond). 2007;7(2):203-4. https://doi.org/10.7861/ clinmedicine.7-2-203

9. MRCP(UK) [Internet]. UK: MRCP(UK); 2018 [cited 2020 Mar 20]. Exam pass rate: Pass rates for MRCP(UK) Diploma and Specialty Certificate Examinations. Available from: https://www.mrcpuk.org/mrcpuk -examinations/results/exam-pass-rates.

10. Bessant R, Bessant D, Chesser A, Coakley G. Analysis of predictors of success in the MRCP(UK) PACES examination in candidates attending a revision course. Postgrad Med J. 2006;82(964):145-9. https://doi.org/10.1136/pmj.2005.035998

11. Verma A, Griffin A, Dacre J, Elder A. Exploring cultural and linguistic influences on clinical communication skills: a qualitative study of International Medical Graduates. BMC Med Educ. 2016;16(1):162. https://doi.org/10.1186/ s12909-016-0680-7

12. Al-Refaie N, Sabra A. Putting doctors through their paces. BMJ. 2016;353. https://doi.org/10.1136/bmj.i1812

13. Larkin J. MRCP(UK) part 2 clinical examination (PACES): examiners reflections. PACES: the training. Clin Med (Lond). 2007;7(2):203-4. https://doi. org/10.7861/clinmedicine.7-2-203

14. Jerrom R, Roper $T$, Murthy $N$. Improving MRCP PACES pass rates through the introduction of a regional multifaceted support framework. BMJ Open Quality. 2017;6(2):e000017. https://doi.org/10.1136/ bmjoq-2017-000017 
15. Stanley AG, Khan KM, Hussain W, Tweed M. Disorganized junior doctors fail the MRCP (UK). Med Teach. 2006;28(1):e40-2. https://doi.org/10.1080/ 01421590600568421

16. Lewis G, Tham TCK, Steele IC, Maxwell AP. Obtaining the MRCP diploma - difficult Olympic hurdles or a straightforward triple jump? The Ulster Med J. 2012;81(3):114-7.

17. McManus IC, Thompson M, Mollon J. Assessment of examiner leniency and stringency ("hawk-dove effect") in the MRCP(UK) clinical examination (PACES) using multi-facet Rasch modelling. BMC Med Educ. 2006;6:42. https://doi.org/10 $.1186 / 1472-6920-6-42$

18. Fylan F. Semi-structured interviewing. In: Miles J, Gilbert P, editors. A handbook of research methods for clinical and health psychology. Oxford: Oxford University Press; 2005. p. 65-77.

19. Dossett LA, Kaji AH, Cochran A. SRQR and COREQ Reporting Guidelines for Qualitative Studies. JAMA Surg. 2021;156(9):875-6. https://doi.org/10.1001/ jamasurg.2021.0525

20. Guest G, Bunce A, Johnson L. How many interviews are enough? An experiment with data saturation and variability. Field Methods. 2006;18(1):59-82. https://doi.org/ $10.1177 / 1525822 \mathrm{X} 05279903$

21. MacLean LM, Meyer M, Estable A. Improving accuracy of transcripts in qualitative research. Qual Health Res. 2004;14(1):113-23. https://doi.org/10.1177/ 1049732303259804

22. Braun V, Clarke V. Using thematic analysis in psychology. Qual Res Psych. 2006;3(2):77-101. https://doi.org/10.1191/ 1478088706qp063oa
23. Nowell LS, Norris JM, White DE, Moules NJ. Thematic analysis: striving to meet the trustworthiness criteria. International Journal of Qualitative Methods. 2017;16(1):1609406917733847. https://doi.org/10.1177/1609406917733847

24. Terry G, Hayfield N. Reflexive thematic analysis. Handbook of qualitative research in education. Cheltenham: Edward Elgar Publishing; 2020. https://doi. org/10.4337/9781788977159.00049

25. Howitt D, Cramer D. Introduction to research methods in psychology. London: Pearson Education; 2007.

26. Bowen GA. Grounded theory and sensitizing concepts. International Journal of Qualitative Methods. 2006;5(3):12-23. https://doi.org/10.1177/ 160940690600500304

27. Braun V, Clarke V. What is coding: complete coding. In: Carmichael $\mathrm{M}$, editor. Successful qualitative research. California: Sage Publications; 2013. p. 206-14.

28. Clarke V, Braun V. Using thematic analysis in counselling and psychotherapy research: a critical reflection. Counselling and Psychotherapy Research. 2018;18(2):10710. https://doi.org/10.1002/capr.12165

29. Whymark DC. Preparing to pass the FRCA: Strategies for exam success. Oxford: Oxford University Press; 2016. https://doi .org/10.1093/med/9780198748687.001.0001

30. Knafl KA, Breitmayer BJ. Triangulation, in qualitative research: issues of conceptual clarity and purpose. In: Morse JM, editor. Qualitative nursing research: a contemporary dialogue. California: Sage Publications; 1991. p. 226-39.

31. Attia M, Edge J. Be(com)ing a reflexive researcher: a developmental approach to research methodology. Open Review of Educational Research. 2017;4(1):33-45. https://doi.org/10.1080/23265507.2017 .1300068 
32. Creswell JW, Creswell JD. Qualitative methods: research design qualitative, quantitative \& mixed methods approaches. 5th ed. California: Sage Publications; 2017.

33. Gertler B. Self-knowledge. London \& New York: Routledge; 2011. https://doi.org/10 $.4324 / 9780203835678$

34. Segool NK, von der Embse NP, Mata AD, Gallant J. Cognitive behavioral model of test anxiety in a high-stakes context: an exploratory study. School Mental Health. 2014;6(1):50-61. https://doi.org/10.1007/ s12310-013-9111-7

35. Bandura A. Self-efficacy. In: Weiner IB, Craighead WE, editors. The Corsini encyclopedia of psychology. John Wiley \& Sons; 2010. p. 1-3. https://doi.org/10 .1002/9780470479216.corpsy0836

36. Zimmerman BJ. Models of self-regulated learning and academic achievement. In: Zimmerman BJ, Schunk DH, editors. Self-regulated learning and academic achievement. New York: Springer; 1989. p. 1-25. https://doi.org/10.1007/978-1-4612 $-3618-4 \_1$

37. Hoekje BJ, Tipton SM. English language and the medical profession: instructing and assessing the communication skills of international physicians. Netherlands: Brill; 2011. https://doi.org/ $10.1163 / 9781780523859$

38. Verma A, Griffin A, Dacre J, Elder A. Exploring cultural and linguistic influences on clinical communication skills: a qualitative study of international medical graduates. BMC Med Educ. 2016;16:162. https://doi.org/10.1186/s12909-016-0680-7

39. Hofstede GH. Culture's consequences: international differences in work-related values. Beverly Hills: Sage Publications; 1984.

40. Hodges B. Validity and the OSCE. Med Teach. 2003;25(3):250-4. https://doi.org/10 $.1080 / 01421590310001002836$
41. McManus IC, Elder AT, Dacre J. Investigating possible ethnicity and sex bias in clinical examiners: an analysis of data from the MRCP(UK) PACES and nPACES examinations. BMC Med Educ. 2013;13:103. https://doi.org/10.1186/1472 $-6920-13-103$

42. Christiansen A, Bell A. Peer learning partnerships: exploring the experience of pre-registration nursing students. J Clin Nurs. 2010;19(5-6):803-10. https://doi.org/ 10.1111/j.1365-2702.2009.02981.x

43. Dunphy BC, Dunphy SL. Assisted performance and the zone of proximal development (ZPD); a potential framework for providing surgical education. Australian Journal of Educational \& Developmental Psychology. 2003;3:48-58.

44. Falchikov N. Peer feedback marking: developing peer assessment. Innovations in Education and Training International. 1995;32(2):175-87. https://doi.org/10.1080/ 1355800950320212

45. Clow D, editor. The learning analytics cycle: closing the loop effectively. Proceedings of the 2nd international conference on learning analytics and knowledge. 2012. p. 134 . https://doi.org/10.1145/2330601.2330636

46. Broadhurst PL. Emotionality and the Yerkes-Dodson Law. Journal of Experimental Psychology. 1957;54(5):34552. https://doi.org/10.1037/h0049114

47. Longyhore DS. Pharmacy student anxiety and success with objective structured clinical examinations. Am J Pharm Educ. 2017;81(1):7. https://doi.org/10.5688/ ajpe 8117

48. Saunders B, Sim J, Kingstone T, Baker S, Waterfield J, Bartlam B, et al. Saturation in qualitative research: exploring its conceptualization and operationalization. Qual Quan. 2018;52(4):1893-907. https:/doi.org/10.1007/s11135-017-0574-8 
49. Elder A, McAlpine L, Bateman N, Dacre J, Kopelman P, McManus C. Changing PACES: developments to the examination in 2009. Clin Med. 2011;11(3):231-4. https://doi.org/10.7861/clinmedicine.11-3 $-231$
50. McManus IC, Elder AT, de Champlain A, Dacre JE, Mollon J, Chis L. Graduates of different UK medical schools show substantial differences in performance on MRCP(UK) Part 1, Part 2 and PACES examinations. BMC Med. 2008;6(5). https://doi.org/10.1186/1741-7015-6-5 